OPEN ACCESS

Edited by:

Kai Lu,

Fujian Agriculture and Forestry

University, China

Reviewed by:

Rui Pang,

Guangdong Academy of Sciences,

China

Leena Thorat,

York University, Canada

*Correspondence:

Can $\mathrm{Li}$

lican790108@163.com

Specialty section:

This article was submitted to Invertebrate Physiology, a section of the journal

Frontiers in Physiology

Received: 10 December 2019

Accepted: 20 October 2020

Published: 25 November 2020

Citation:

Ding Y-J, Li G-Y, XU C-D, Wu Y,

Zhou Z-S, Wang S-G and Li C (2020)

Regulatory Functions of Nilaparvata lugens GSK-3 in Energy and Chitin

Metabolism.

Front. Physiol. 11:518876. doi: 10.3389/fphys.2020.518876

\section{Regulatory Functions of Nilaparvata lugens GSK-3 in Energy and Chitin Metabolism}

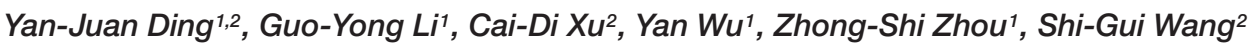 \\ and Can $\mathrm{Li}^{1 *}$
}

' Guizhou Provincial Key Laboratory for Rare Animal and Economic Insect of the Mountainous Region, Guizhou Provincial Engineering Research Center for Biological Resources Protection and Efficient Utilization of the Mountainous Region, College of Biology and Environmental Engineering, Guiyang University, Guiyang, China, ${ }^{2}$ College of Life and Environmental Sciences, Hangzhou Normal University, Hangzhou, China

Glucose metabolism is a biologically important metabolic process. Glycogen synthase kinase (GSK-3) is a key enzyme located in the middle of the sugar metabolism pathway that can regulate the energy metabolism process in the body through insulin signaling. This paper mainly explores the regulatory effect of glycogen synthase kinase on the metabolism of glycogen and trehalose in the brown planthopper (Nilaparvata lugens) by RNA interference. In this paper, microinjection of the target double-stranded GSK-3 (dsGSK-3) effectively inhibited the expression of target genes in N. lugens. GSK-3 gene silencing can effectively inhibit the expression of target genes (glycogen phosphorylase gene, glycogen synthase gene, trehalose-6-phosphate synthase 1 gene, and trehalose6-phosphate synthase 2 gene) in $N$. lugens and trehalase activity, thereby reducing glycogen and glucose content, increasing trehalose content, and regulating insect trehalose balance. GSK-3 can regulate the genes chitin synthase gene and glucose6-phosphate isomerase gene involved in the chitin biosynthetic pathway of $N$. lugens. GSK-3 gene silencing can inhibit the synthesis of chitin N. lugens, resulting in abnormal phenotypes and increased mortality. These results indicated that a low expression of GSK-3 in N. lugens can regulate the metabolism of glycogen and trehalose through the insulin signal pathway and energy metabolism pathway, and can regulate the biosynthesis of chitin, which affects molting and wing formation. The relevant research results will help us to more comprehensively explore the molecular mechanism of the regulation of energy and chitin metabolism of insect glycogen synthase kinases in species such as $N$. lugens.

Keywords: Nilaparvata lugens, RNA interference, glycogen synthase kinase 3, glycogen and trehalose metabolism, chitin metabolism

\section{INTRODUCTION}

Rice is one of the most important food crops grown in large quantities in Southeast Asian countries (Kang et al., 2019). However, rice is threatened by hundreds of pests throughout many stages, from planting to storage (Ghaffar et al., 2011). Delphacidae are one of the most serious rice pests, with the family including insects such as Laodelphgax striatellus, Sogatella furcifera, and Nilaparvata lugens. Since $N$. lugens has a single feeding habit feeding on rice, and is also a carrier of rice rough stunt 


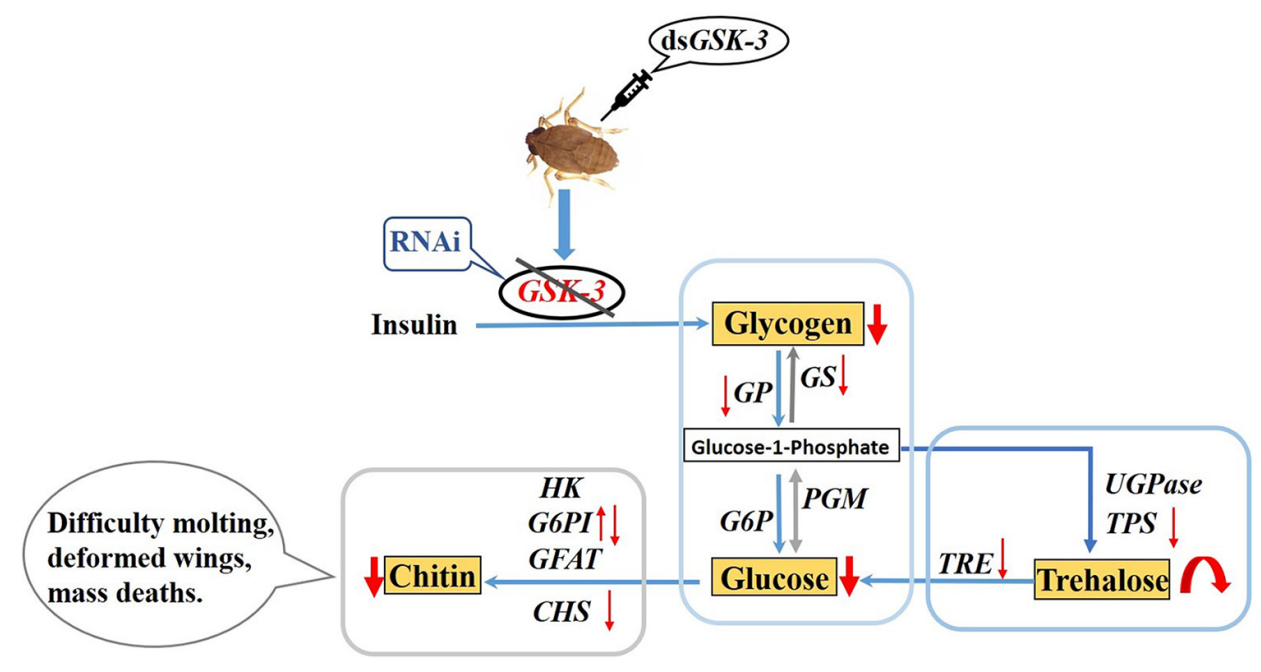

GRAPHICAL ABSTRACT | Regulation of GSK-3 on energy and chitin metabolism of Nilaparvata lugens.

virus (RRSV) and grass stunt virus (Zhu et al., 2017), it has become the most serious type of Delphacidae (Jing et al., 2017; Zhang et al., 2018). At present, most of the chemical pesticides are used to control $N$. lugens, but because of its resistance to a large number of insecticides, the control effect is not satisfactory. In addition, the use of chemical pesticides poses a strong threat to the ecological environment (Diptaningsari et al., 2019).

Glucose metabolism is an important energy metabolism process in living organisms, supplying energy for life activities such as the growth and development of organisms (Carlson et al., 2018). Glycogen is the main form of glucose stored in insects and supplies energy according to the needs of different tissues (Prats et al., 2018). In animals, glucose can be converted to glycogen under the catalysis of glycogen synthase (Klotz and Forchhammer, 2017; Chang et al., 2018), and glycogen degradation requires the action of glycogen phosphorylase (Yamada et al., 2018). Glycogen is mainly stored in the fat bodies of insects and is converted to glucose or trehalose if necessary (Duran et al., 2012; Tang et al., 2012). In insects, glycogen is not a major energy substance, but it is used together with trehalose as a spare sugar to maintain glucose availability (Santiago-Martínez et al., 2016; Prats et al., 2018).

Trehalose is a non-reducing disaccharide unique to insects because it forms the main hemolymph sugar, also known as the "blood sugar" of insects (Zhang et al., 2017b). In fact, trehalose is synthesized by glucose under the catalysis of trehalose6-phosphate synthase (Matsuda et al., 2015). In addition to providing energy and functioning as a carbon source, trehalose also has bio-protective properties that protects cells and proteins in extreme environments such as cold, oxidation, hypoxia, and dryness (Matsuda et al., 2015; Wen et al., 2016). The degradation of trehalose occurs mainly during the production of glucose under the catalysis of trehalase, which provides energy for life activities such as insect flight. There are two forms of trehalase in insects, soluble trehalase and membrane-bound trehalase (Tang et al., 2017). The synthetic substrates of trehalose, uridine diphosphate glucose and phosphate-6-glucose, can be derived from the decomposition of glycogen (Mitsumasu et al., 2010). Therefore, glycogen metabolism in insects is closely related to the formation and utilization of trehalose.

Trehalase can regulate chitin synthesis in insects (Zhang et al., 2017a). Chitin is the main structural material that constitutes the complex exoskeleton of insects and is found in many insects and arthropods (Zhu et al., 2016). In addition to trehalase, the chitin biosynthetic pathway also includes hexokinase (HK), glucose-6-phosphate isomerase, and glutamine; fructose 6phosphate transaminase (GFAT), glucosamine-6-phosphate $\mathrm{N}$-acetyltransferase (GNPNA), phosphor acetylglucosamine mutase (PAGM), UDP-N-acetylglucosamine pyrophosphorylase (UAP), and chitin synthase are essential for insect growth and development (Merzendorfer, 2006; Guo et al., 2019). Chitin is the main component of the peritrophic membrane (PM) in the midgut of insects. PM is the natural immune barrier of insects, which can resist the invasion of bacteria, viruses, and other pathogens (Wang and Granados, 2010). Studies on insects such as Drosophila, Bombyx mori, and Locust have found that the obstruction of chitin synthesis can lead to abnormal phenomena such as insect molting, increased mortality, and ovarian hypoplasia (Yang et al., 2015; Xu et al., 2017; Liu and Klein, 2018). Tang et al. (2016) and Chen et al. (2018) found that after RNA interference inhibited the expression of the N. lugens trehalase gene and trehalose synthase gene, the chitin content was significantly reduced, and high mortality and difficulty in molting were observed. However, there are few studies on the metabolism of chitin in insects with respect to the Glycogen synthase kinase (GSK-3) gene.

In recent years, there have been more and more studies on insect energy metabolism. In addition, various metabolic pathways of insects have become increasingly clear (Arrese and Soulages, 2010; Yang et al., 2014). Glycogen synthase kinase 3 is a key enzyme located in the middle of the sugar metabolism pathway (Mury et al., 2016). Woodgett et al. (1993) isolated 
and purified two subtypes from skeletal muscle, GSK-3 $\alpha$ and GSK-3 $\beta$, which are encoded by two different genes and are widely expressed in different tissues and cells (Maqbool et al., 2016). GSK-3 is involved in the regulation of various signaling pathways, such as insulin, Wnt/ $\beta$-catenin, Hedgehog, and Notch signaling pathways, which play important roles in regulating cell differentiation, metabolism, apoptosis, and gene expression (Wei and Wei, 2015; Khan et al., 2017; Sato and Shibuya, 2018). In insects, GSK-3 can inactivate glycogen synthase by phosphorylating glycogen synthase, inhibit the final step of glycogen synthesis, and also block the transmission of the insulin signaling pathway to inhibit glycogen synthesis (Frame and Cohen, 2001; Contreras et al., 2016). The conversion between glycogen and trehalose is inseparable, so the expression of GSK-3 has an important influence on the anabolism of glycogen and trehalose.

The main purpose of this study was to microinject doublestranded RNA into $N$. lugens, thereby silencing the expression of the corresponding gene and achieving RNA interference. This method has been widely used in insect gene research in species such as N. lugens (Yu et al., 2013; Qiu et al., 2016; Shi et al., 2016). Once the expression of GSK-3 in insects is abnormal, the process of glucose metabolism in the body will be unbalanced, and the development of insects, molting, and other life activities will be abnormal (Avonce et al., 2006; Mitsumasu et al., 2010; Shukla et al., 2015). Therefore, this study aimed to investigate the regulation of glycogen synthase kinase on energy metabolism and the chitin synthesis pathway in $N$. lugens. It provides a theoretical basis for pest control through energy and chitin metabolism.

\section{MATERIALS AND METHODS}

\section{Insects}

All the $N$. lugens used in this study were collected from the China Rice Research Institute and were kept in our laboratory. Rice varieties were insect-resistant rice TN1 (Taichung Native 1 ). Before rice planting, we first immersed rice seeds in warm water at about $70^{\circ} \mathrm{C}$ for about $10 \mathrm{~min}$ to break dormancy; then, seeds were soaked in tap water and placed in a $30^{\circ} \mathrm{C}$ artificial climate incubator for $24 \mathrm{~h}$. Then, we washed the seeds several times with tap water, wrapped the seeds with wet gauze, and then placed them in a $30^{\circ} \mathrm{C}$ artificial climate incubator for $24-48 \mathrm{~h}$. Seeds were germinated and sown in plastic pots, and appropriate fertilization promoted seedling growth. After the rice seedlings grew to about $10 \mathrm{~cm}$, they were planted in the field. At the middle of the tillering stage, rice was moved to the insect cage, and rice was replaced every $2-3$ days. The conditions for feeding $N$. lugens were as follows: temperature $26^{\circ} \mathrm{C} \pm 1^{\circ} \mathrm{C}$, photoperiod $16 \mathrm{~h} / 8 \mathrm{~h}$, and relative humidity of $70 \%$.

\section{Total RNA Extraction and cDNA Synthesis}

Total RNA from N. lugens was extracted according to the Trizol kit instructions (Invitrogen, Carlsbad, CA, United States). After extraction, the mass of total RNA was detected by $1 \%$ agarose gel electrophoresis, and then the concentration and purity of RNA were measured using a NanoDrop 2000 spectrophotometer (Thermo Fisher Scientific, Waltham, MA, United States). The Prime Link ${ }^{\circledR}$ RT Reagent Kit (NARISHIGE, Japan) with gDNA Eraser Kit was used to configure the system and synthesize the first strand of cDNA.

\section{Synthesis of dsRNA}

We designed and synthesized specific primers based on GSK3 dsRNA specific fragments. Then, PCR amplification was performed, and the amplified product was subjected to T cloning. The cross-PCR reaction was then carried out using a primer with a T7 promoter. Related primer sequences are shown in Table 1. The synthesis of dsGSK-3 was performed according to the instructions of the T7 RiboMAX ${ }^{\mathrm{TM}}$ Express RNAi System kit (Promega Corporation, Madison, United States), and the concentration of dsGSK-3 was determined by a NanoDrop ${ }^{\text {TM }}$ 2000 spectrophotometer. The same method was used to synthesize GFP dsRNA as a control group (Tang et al., 2010; Zhao et al., 2014). In addition, a trehalose solution and a glucose solution at a concentration equal to dsRNA were prepared.

\section{Microinjection of $\boldsymbol{N}$. lugens}

The injection group of this experiment included the dsGSK-3 only injection group, the dsGSK-3 and glucose mixed injection group, the dsGSK-3 and trehalose (Sigma-Aldrich, Saint Louis, MO 63103, United States) mixed injection group, and the dsGFP injection group as a control. For the mixed injection group, dsGSK-3 was mixed in equal volume with an equal concentration of trehalose or glucose solution before injection. The dsRNA was injected into a standard capillary to determine the volume that the microinjector (NARISHIGE, Japan) pumped each time. Then, we adjusted the volume of the pumped dsRNA by nitrogen pressure so that the pumped volume was in accordance with the amount required for injection. Fifth instar N. lugens was anesthetized with $\mathrm{CO}_{2}$, and then placed in a disposable culture dish with an agar plate on the abdomen. The injection site was the softer part of the first pair of feet in the middle of the foot. The

TABLE 1 | Primers used for the synthesis of dsRNA for GFP and GSK3 genes.

\begin{tabular}{|c|c|c|c|c|}
\hline Gene & Application type & Primer set & Forward primer $\left(5^{\prime}-3^{\prime}\right)$ & Reverse primer $\left(5^{\prime}-3^{\prime}\right)$ \\
\hline NIGSK-3 & dsRNA synthesis & dsNIGSK-3 dsNIGSK-3-T7 & $\begin{array}{l}\text { CTGCGACAGCGGCGAAATG } \\
\text { T7-CTGCGACAGCGGCGAAATG }\end{array}$ & $\begin{array}{l}\text { CGGTGACAGATGCCCAGCGAGT } \\
\text { T7-CGGTGACAGATGCCCAGCGAGT }\end{array}$ \\
\hline GFP & dsRNA synthesis & dsNIGFP dsNIGFP-T7 & $\begin{array}{l}\text { AAGGGCGAGGAGCTGTTCACCG } \\
\text { T7-AAGGGCGAGGAGCTGTTCACCG }\end{array}$ & $\begin{array}{l}\text { CAGCAGGACCATGTGATCGCGC } \\
\text { T7-CAGCAGGACCATGTGATCGCGC }\end{array}$ \\
\hline T7 & dsRNA synthesis & & GGATCCTAATACGACTCACTATAGG & \\
\hline
\end{tabular}


injection volume of each $N$. lugens was $200 \mathrm{ng}$, with 100 injections per treatment group. The samples were taken at 48 and $72 \mathrm{~h}$ after injection for determination of trehalose, glucose, glycogen content, and trehalase activity and the expression of related genes (Tang et al., 2017).

\section{Expression Studies of Key Genes After GSK-3 RNAi}

The expressions of key genes in the energy metabolism pathway, insulin signaling pathway, and chitin synthesis pathway were detected by qRT-PCR at 48 and $72 \mathrm{~h}$ after injection of $N$. lugens. Parallel sampling was taken; three tubes per treatment group, five $N$. lugens per tube, and three tubes of parallel cDNA were obtained for each sample and were stored in a $-80^{\circ} \mathrm{C}$ refrigerator. During the experiment, three samples of cDNA per tube were obtained, and nine data points were obtained from three tubes of parallel cDNA. Each sample was presented as the average \pm standard error to ensure the reliability of the data. The qRT-PCR reaction system (Bio-Rad Laboratories Inc.) $(10 \mu \mathrm{L})$ was as follows: $5 \mu \mathrm{L}$ SYBR Premix Ex Taq (SYBR Green Premix Ex Taq, Takara, Japan); $0.4 \mu \mathrm{L}$ upstream/downstream primer; $1 \mu \mathrm{L}$ cDNA; and $3.2 \mu \mathrm{L}$ sterile ultrapure water. Quantitative primers are shown in Table 2, with $18 \mathrm{~S}$ as the internal control gene. The reaction procedure was as follows: pre-denaturation at $95^{\circ} \mathrm{C}$ for $10 \mathrm{~s}$, melting at $95^{\circ} \mathrm{C}$ for $5 \mathrm{~s}$, annealing at $59^{\circ} \mathrm{C}$ for $30 \mathrm{~s}$, 40 cycles (Zhang et al., 2017b).

\section{Determination of Trehalose, Glucose, Total Glycogen Content, and Trehalase Activity}

Each treatment and control material was added, after which 100 $\mu \mathrm{L}$ of phosphate buffered saline (PBS) was added, ground, and then added to $100 \mu \mathrm{L}$ of PBS; sonication was performed until to no blocky structure was observed, after which the samples were crushed, added to $800 \mu \mathrm{L}$ of PBS, and centrifuged at $1,000 \mathrm{~g}$ for $20 \mathrm{~min}$ at $4^{\circ} \mathrm{C}$. Then, $350 \mu \mathrm{L}$ of supernatant was collected and ultracentrifuged for $60 \mathrm{~min}$ at $4^{\circ} \mathrm{C}, 20,800 \mathrm{~g}$. The $1,000 \mathrm{~g}$ centrifugation supernatant was used for determination of the protein concentration, glycogen concentration, and trehalose concentration. The supernatant after ultracentrifugation was used for the determination of the glucose content (supernatant), soluble trehalase activity (TRE1), and protein (Pr1). In addition, the pellet was suspended in PBS and used for the determination of the glucose content (suspension), membrane-bound trehalase (TRE2), and protein (Pr2). The specific steps are described in the kit instructions. In short, $75 \mu \mathrm{L}$ of $40 \mathrm{mM}$ trehalose (SigmaAldrich, Saint Louis, Mo 63103 United States) and $165 \mu \mathrm{L}$

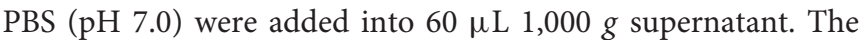

TABLE 2 | Primers used for qRT-PCR measurements of metabolism key genes.

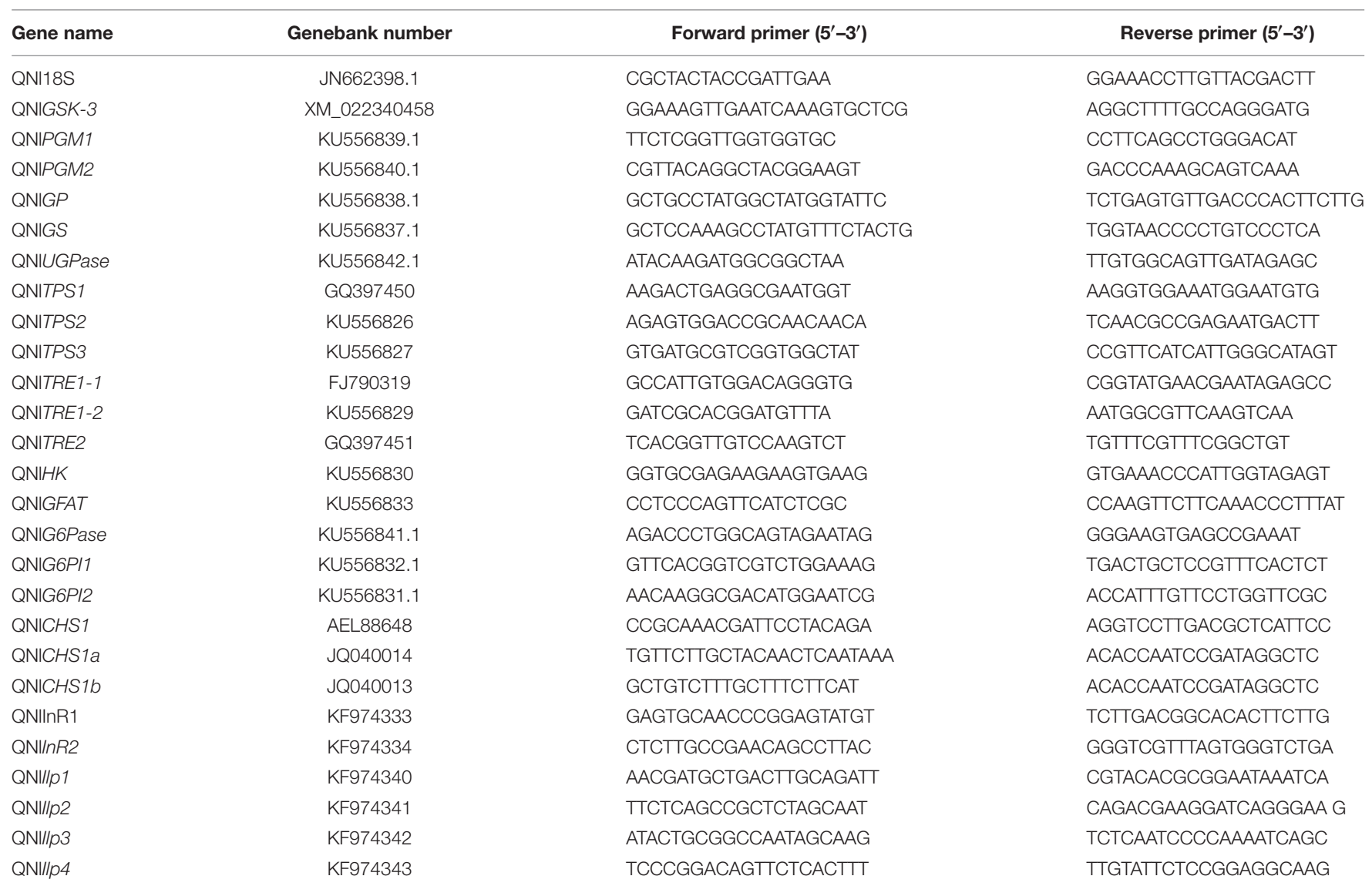


mixture was immersed in water for $60 \mathrm{~min}$ at $37^{\circ} \mathrm{C}$ and $5 \mathrm{~min}$ at $100^{\circ} \mathrm{C}$. TRE activity was measured with glucose detection kit (Sigma-Aldrich) using supernatant $(50 \mu \mathrm{L})$. The protein content in $1,000 \mathrm{~g}$ supernatant, ultracentrifugation supernatant, and suspension was determined by BCA Protein Assay Kit (Beyotime, China). Trehalose content was measured by anthrone method, and $30 \mu \mathrm{L} 1 \% \mathrm{H}_{2} \mathrm{SO}_{4}$ was added to $30 \mu \mathrm{L}$ samples. The mixture was bathed in water at $90^{\circ} \mathrm{C}$ for $10 \mathrm{~min}$ and in ice for $3 \mathrm{~min}$. After $30 \mu \mathrm{L} \mathrm{30 \%} \mathrm{KOH}$ was added, the mixture was again bathed in water at $90^{\circ} \mathrm{C}$ for $10 \mathrm{~min}$ and in ice for $3 \mathrm{~min}$. Then, 600 $\mu \mathrm{L}$ developer $\left(0.02 \mathrm{~g}\right.$ fluorenone $\left.+100 \mathrm{ml} 80 \% \mathrm{H}_{2} \mathrm{SO}_{4}\right)$ was added, water bathed at $90^{\circ} \mathrm{C}$ for $10 \mathrm{~min}$, and cooled in an ice bath. The absorbance of the sample was measured at $630 \mathrm{~nm}$ with a microplate reader. One hundred sixty microliter of the supernatant was obtained after centrifugation of $1,000 \mathrm{~g}$ for the determination of glycogen content. Six hundred microliter of anthrone sulfate reagent was added to the sample, placed in a water bath at $90^{\circ} \mathrm{C}$ for $10 \mathrm{~min}$, and then cooled in an ice bath. The absorbance of the sample was measured at $625 \mathrm{~nm}$ with a microplate reader. The Glucose Assay Kit (SIGMA) was used to determine the glucose content in the supernatant and pellet suspension obtained after centrifugation at 20,800 g. $150 \mu \mathrm{L}$ of the sample was placed into an EP (Eppendorf), and then $30 \mu \mathrm{L}$ of $2 \mathrm{~N} \mathrm{H}_{2} \mathrm{SO}_{4}$ was added to stop the reaction after $30 \mathrm{~min}$ in a $37^{\circ} \mathrm{C}$ water bath, and the absorbance of the sample at $540 \mathrm{~nm}$ was then measured using a microplate reader.

\section{Chitin Analysis}

The detection method of the proportion of chitin in the brown planthopper refers to the "Insect Biochemical and Molecular Biology Experimental Technology" compiled by Cao and Gao (2009), with appropriate modifications. Two glass tubes were connected to both ends of a rubber tube, about 30-50 cm long. Another test tube with a rubber plug with holes was taken and the glass tube was inserted at one end of the rubber tube into the rubber plug, and the other end was passed into the water to prevent the lye from splashing out. $40 \mathrm{~N}$. lugens was taken, three groups were paralleled, and then dried in an oven at $50^{\circ} \mathrm{C}$. The $N$. lugens dried to a constant weight was weighed and recorded as W1. The dried insect body was poured into a test tube, $5 \mathrm{~mL}$ saturated potassium hydroxide solution was added, and it was heated in a glycerin bath at $160^{\circ} \mathrm{C}$ until the insect body developed a transparent film. The residue was filtered, rinsed carefully with water, dried in an oven at $50^{\circ} \mathrm{C}$, weighed, and counted as W2. The relative content of chitin $(\%)=(\mathrm{W} 2$ $/ \mathrm{W} 1) \times 1.26 \times 100(\%)$, where 1.26 is the ratio of relative molecular mass of acetylglucosamine to glucosamine.

\section{Statistical Analyses}

The average CT value of the three replicate wells was used for calculation, and the final data were the mean \pm standard error. Then, the $2^{-\Delta \Delta C T}$ formula was used to calculate the CT value of the dsGFP group injected into $N$. lugens. The $2^{-\Delta \Delta C T}$ calculation formula is as follows:

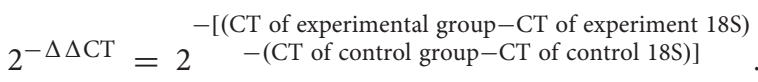

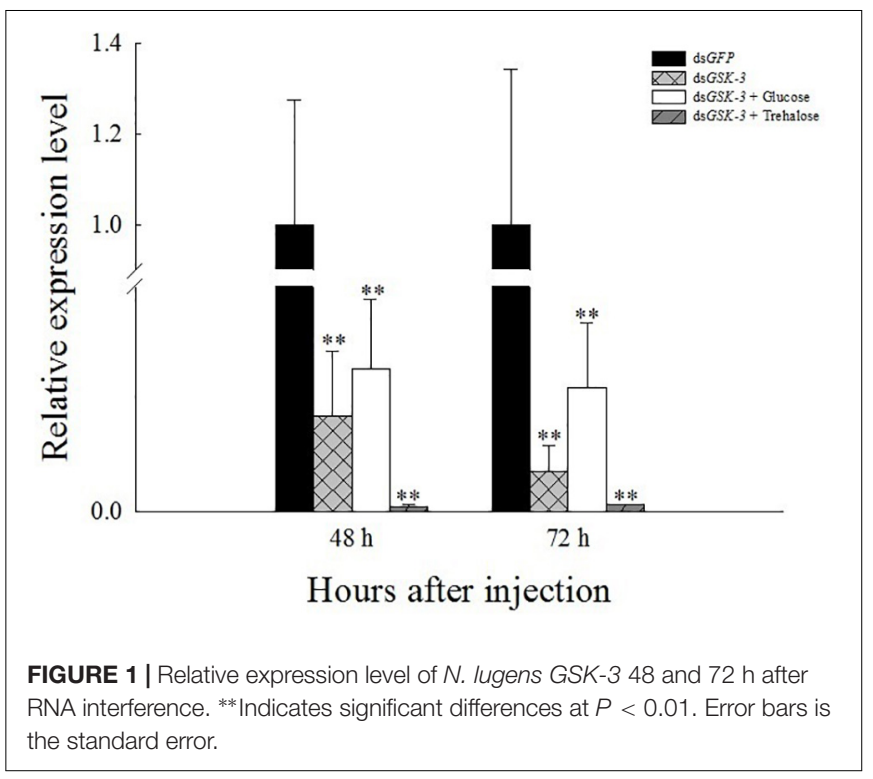

Charts were drawn using Excel software, statistical analysis was performed using STATISTICA 8.0 and SigmaPlot 10.0, and the significance difference test was performed using one-way ANOVA ( $*$ indicates $P<0.05$, the difference is significant; ${ }^{* *}$ indicates $P<0.01$, the difference is extremely significant).

\section{RESULTS}

\section{Expression of GSK-3 After RNAi}

Compared with the injection of the dsGFP group, the expression levels of GSK-3 mRNA in the three treatment groups were significantly decreased at 48 and $72 \mathrm{~h}$ after injection. Among them, the dsGSK-3 and trehalose mixed injection group decreased most obviously $(P<0.01)$ (Figure 1). This result indicates that the injection of dsGSK-3, a mixture of dsGSK-3 and glucose, a mixture of dsGSK-3, and trehalose can significantly reduce the expression of GSK-3.

\section{Effects of GSK-3 RNAi on Glycogen, Glucose, and Trehalose Contents}

Compared with the injection of the dsGFP group, glycogen and glucose levels were extremely significantly decreased or significantly decreased $48 \mathrm{~h}$ after injection (Figures 2A,B), and the trehalose content increased extremely significantly $48 \mathrm{~h}$ after dsGSK-3 injection $(P<0.01)$ (Figure 2C). The glycogen, glucose, and trehalose contents were significantly decreased or extremely significantly decreased $72 \mathrm{~h}$ after dsGSK-3 injection (Figure 2); the glucose and glycogen contents were significantly increased after injection of a mixture of dsGSK-3 and glucose $(P<0.05)$ (Figures $2 \mathrm{~A}, \mathbf{B})$, and the glycogen and glucose contents were restored to a level similar to that observed in the control group after injection of a mixture of dsGSK-3 and trehalose (Figures 2A,B). In the two mixed injection groups, the change in the trehalose content was not significant (Figure 2C). 

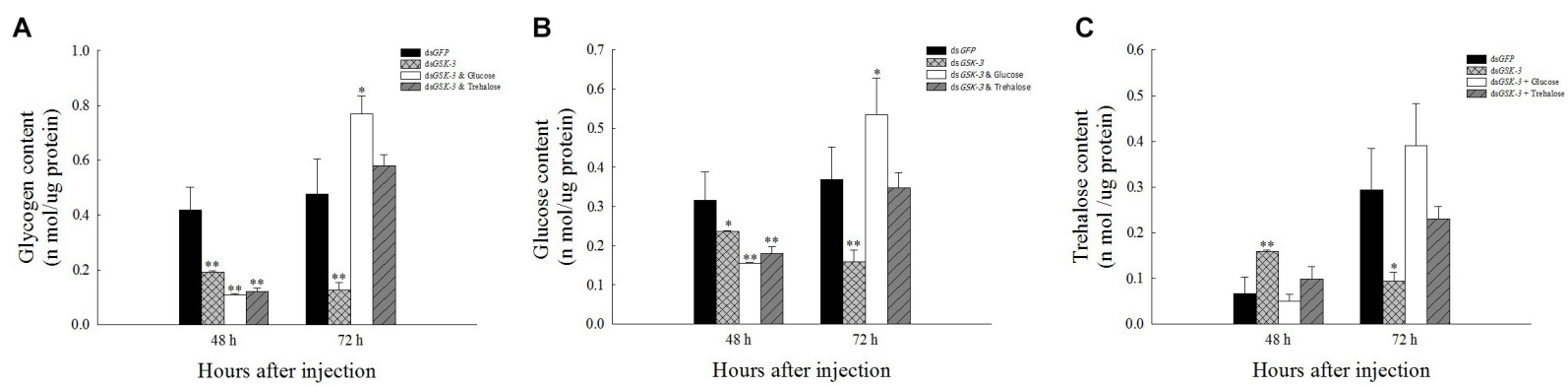

FIGURE 2 | Effect of GSK-3 RNA interference on glycogen, glucose, and trehalase contents of N. lugens. Changes in glycogen (A), glucose (B), and trehalose (C) contents in $N$. lugens were observed at 48 and $72 \mathrm{~h}$ after injection in each treatment group. *Indicates significant differences at $P<0.05$ and $* *$ indicates significant differences at $P<0.01$. Error bars is the standard error.

A

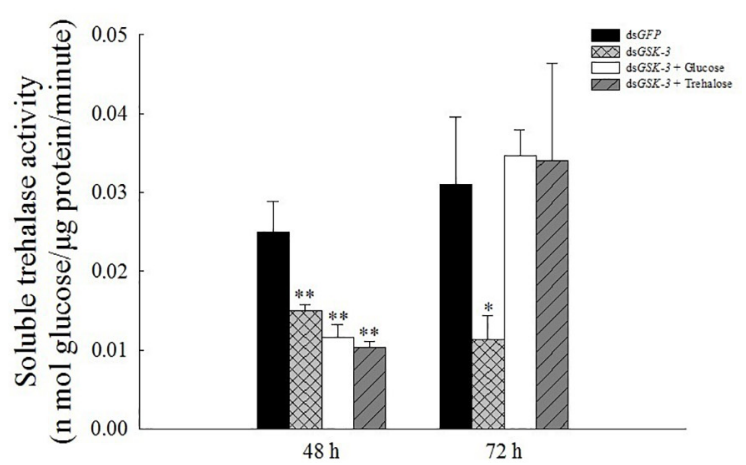

Hours after injection
B

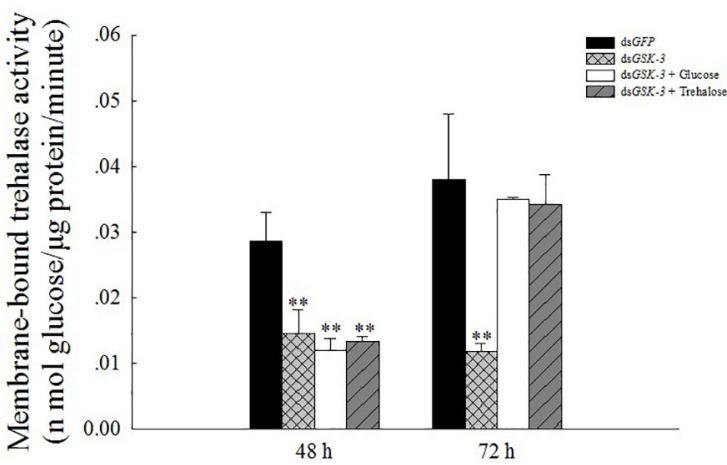

Hours after injection

FIGURE 3 | Effect of GSK-3 RNA interference on trehalase activity of N. lugens. The soluble trehalase (A) and membrane-bound trehalase (B) activities of N. Iugens were observed $48 \mathrm{~h}$ and $72 \mathrm{~h}$ after injection in each treatment group. *Indicates significant differences at $P<0.05$ and ${ }^{* *}$ indicates significant differences at $P<0.01$. Error bars is the standard error.

\section{Effects of GSK-3 RNAi on Two Kinds of Trehalase in N.lugens}

The results of the trehalase activity assay showed that the soluble trehalase and membrane-bound trehalase activities of the three treatment groups were extremely significantly decreased $48 \mathrm{~h}$ after injection $(P<0.01)$ (Figures 3A,B). The two trehalase activities were significantly reduced $72 \mathrm{~h}$ after dsGSK-3 injection $(P<0.01)$ (Figures 3B,C), and the trehalase activity of the two mixed injection groups returned to a level similar to the control group (Figure 3).

\section{Expression of Chitin Synthesis Pathway-Related Genes After GSK-3 RNAi}

The expression of TRE1-1 and TRE2 decreased or decreased significantly compared with the injection of dsGFP after RNAi inhibited the expression of $N$. lugens GSK-3. The expression of TRE1-2 increased significantly $48 \mathrm{~h}$ after injection of a mixture of dsGSK-3 and trehalose $(P<0.01)$ and decreased slightly $72 \mathrm{~h}$ after injection, and the expression of TRE1-2 also increased significantly after injection of a mixture of dsGSK-3 and glucose
$(P<0.01$, Figure 4A). There was no significant change in the expression of GFAT and $H K$ genes after dsGSK-3 and a mixture of dsGSK-3 and glucose injection (Figure 4B). After inhibition, the expression level of G6PI showed a trend of increasing first and then decreasing (Figure 4C). The expression of CHS1a was extremely significantly increased $48 \mathrm{~h}$ after dsGSK-3 injection $(P<0.01)$, the expression of $C H S 1 b$ was extremely significantly decreased after injection $(P<0.01)$, and the expression of $C H S$ was not significantly changed $48 \mathrm{~h}$ after injection of a mixture of dsGSK-3 and glucose. Injection of a mixture of dsGSK-3 and trehalose showed significant inhibition of CHS expression $(P<0.05)$. The expression levels of $C H S$ in each treatment group decreased or decreased extremely significantly $72 \mathrm{~h}$ after injection (Figure 4D).

\section{Expression of Genes Involved in the Energy Metabolism Pathway After GSK-3 RNAi}

Compared with the control group dsGFP, the expression levels of TPS1 and TPS2 were extremely significantly decreased after treatment. The expression of TPS3 increased but was not 


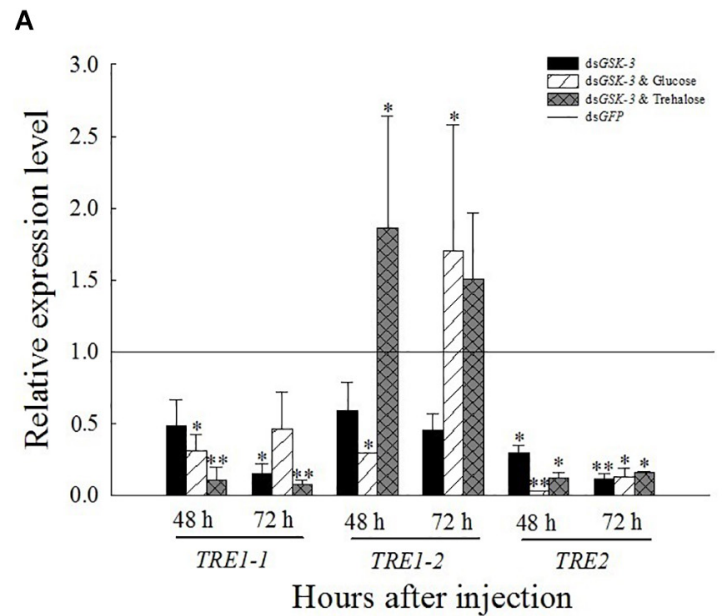

C

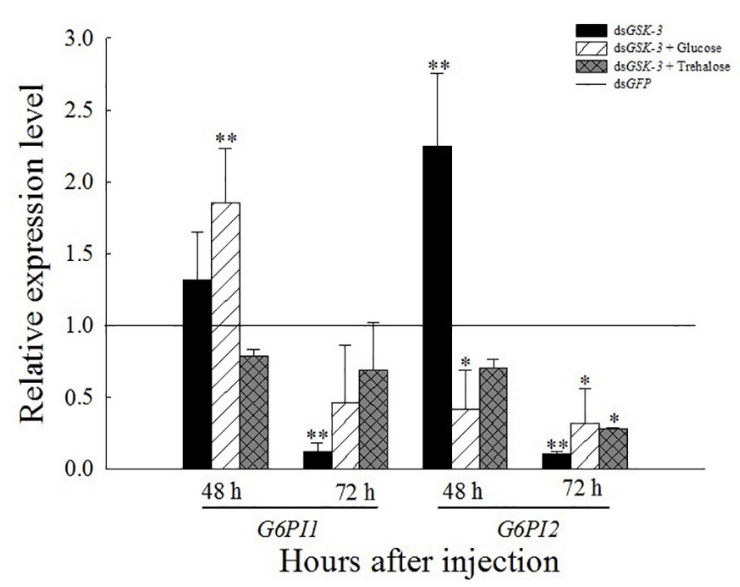

B

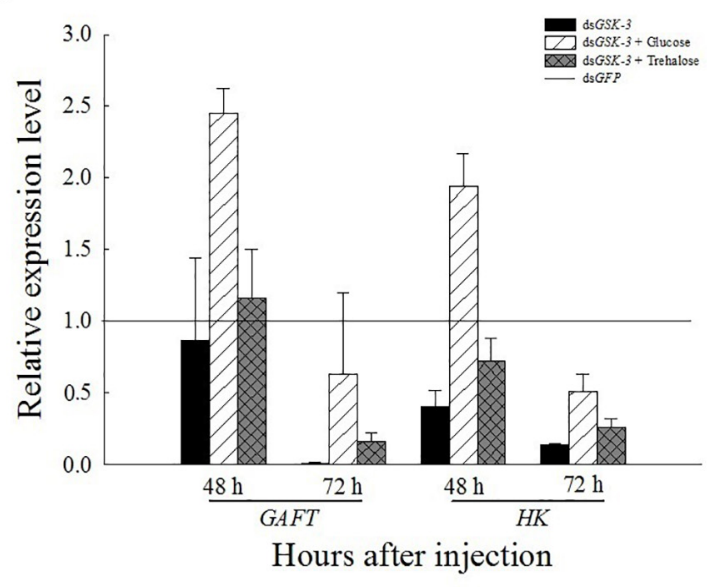

D

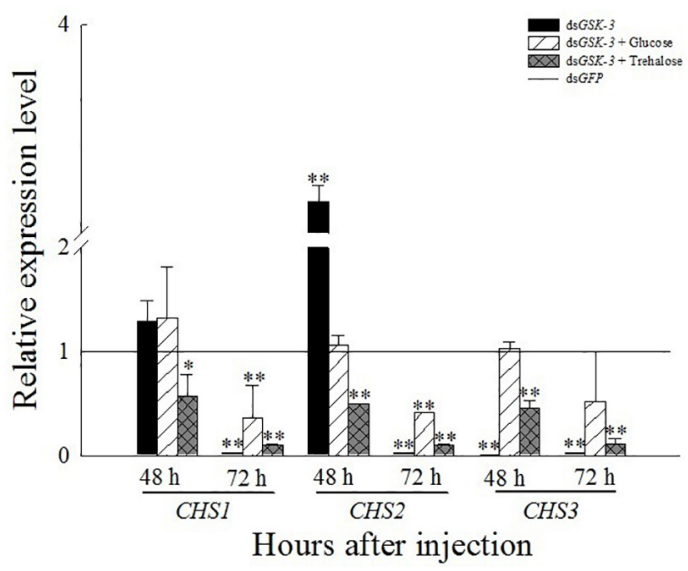

FIGURE 4 | Expression levels of regulated genes in the chitin synthesis pathway after GSK-3 RNA interference. The relative expression levels of three TRE genes (A), GFAT and HK genes (B), G6PI genes (C), and CHS (D) genes after dsRNA injection compared with the control dsGFP. ${ }^{*}$ Indicates significant differences at $P<0.05$ and ${ }^{*}$ indicates significant differences at $P<0.01$. Error bars is the standard error.

significant $48 \mathrm{~h}$ after injection of dsGSK-3 and a mixture of dsGSK-3 and glucose (Figure 5A). The expression of PGM1 was extremely significantly increased $72 \mathrm{~h}$ after dsGSK-3 and a mixture of dsGSK-3 and glucose injection, and there was no significant change in PGM2 expression (Figure 5B). The expression of GS and GP decreased extremely significantly after injection in each treatment group (Figure 5D). The expression of $G 6 P$ increased significantly $48 \mathrm{~h}$ after dsGSK-3 injection and decreased after $72 \mathrm{~h}$. The expression of UGPase and PFK did not change significantly (Figure 5B).

\section{Expression of Insulin Signaling Pathway-Related Genes After GSK-3 RNAi}

After RNAi inhibited the expression of GSK-3, the expression levels of $I n R, I l p 1$, and $I l p 2$ were extremely significantly lower than those of dsGFP $(P<0.01)$ (Figure 6). The expression of Ilp3 and $I l p 4$ was significantly or extremely significantly decreased
$48 \mathrm{~h}$ after injection, and increased extremely significantly $72 \mathrm{~h}$ after the injection of a mixture of dsGSK-3 and glucose. The expression of Ilp 4 increased extremely significantly $72 \mathrm{~h}$ after dsGSK-3 injection (Figure 6B).

\section{Analysis of Phenotype, Malformation Rate, Mortality, and Chitin Content After GSK-3 RNAi}

After injection of dsRNA, the death rate of N. lugens increased, and various abnormal phenotypes appeared. Compared with the control group injected with dsGFP, the mortality rate was significantly increased at $48 \mathrm{~h}$ after mixed injection of dsGSK3 and trehalose and $72 \mathrm{~h}$ after the interference of dsGSK-3 $(P<0.05)$ (Figure 7A). N. lugens in each treatment group showed abnormal phenotypes, including molting deformities and wing deformities (Figure 7D); the deformity rate of the mixed injection group was higher than that of the dsGSK-3 alone injection group (Figure 7B). 
A

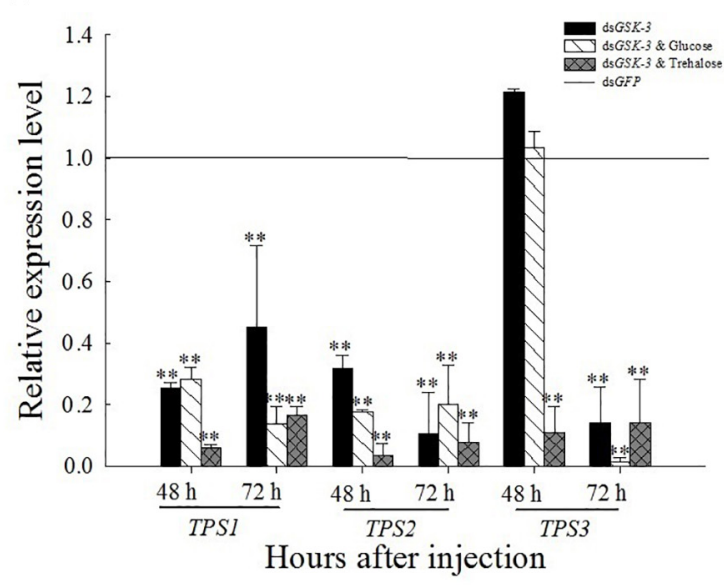

C

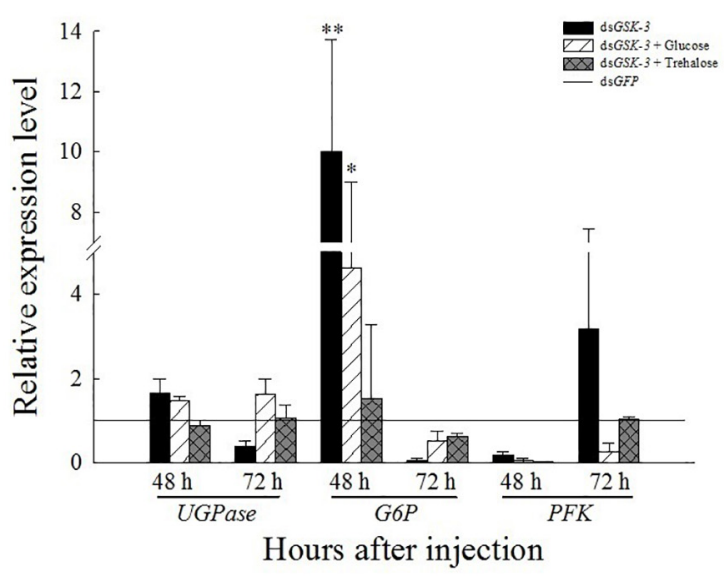

B

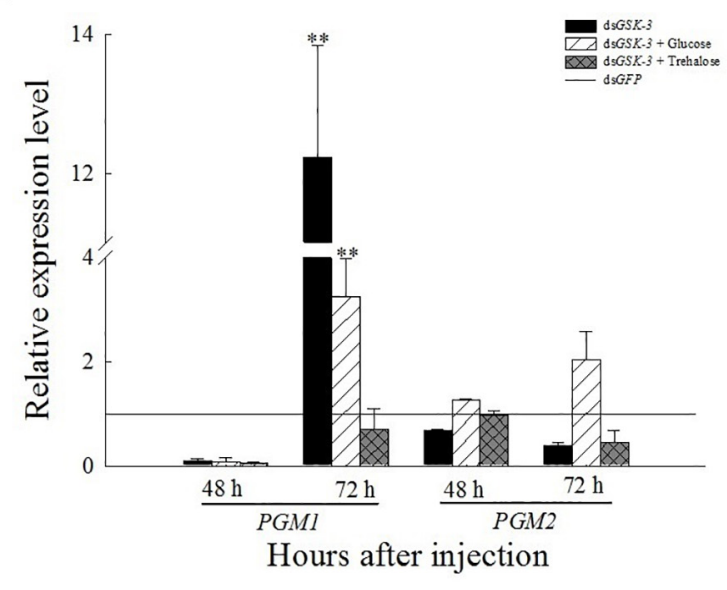

D

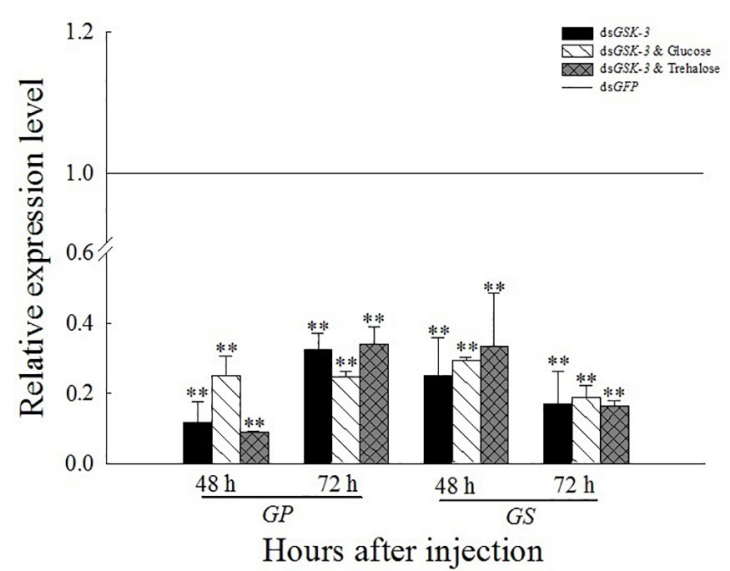

FIGURE 5 | Expression levels of regulated genes in the energy metabolism pathway after GSK-3 RNA interference. The relative expression levels of TPS genes (A), PGM genes (B), UGPase, G6P, and PFK genes (C), and GP and GS genes (D) were compared with the control dsGFP after injection in each treatment group. *Indicates significant differences at $P<0.05$ and ${ }^{*}$ indicates significant differences at $P<0.01$. Error bars is the standard error.
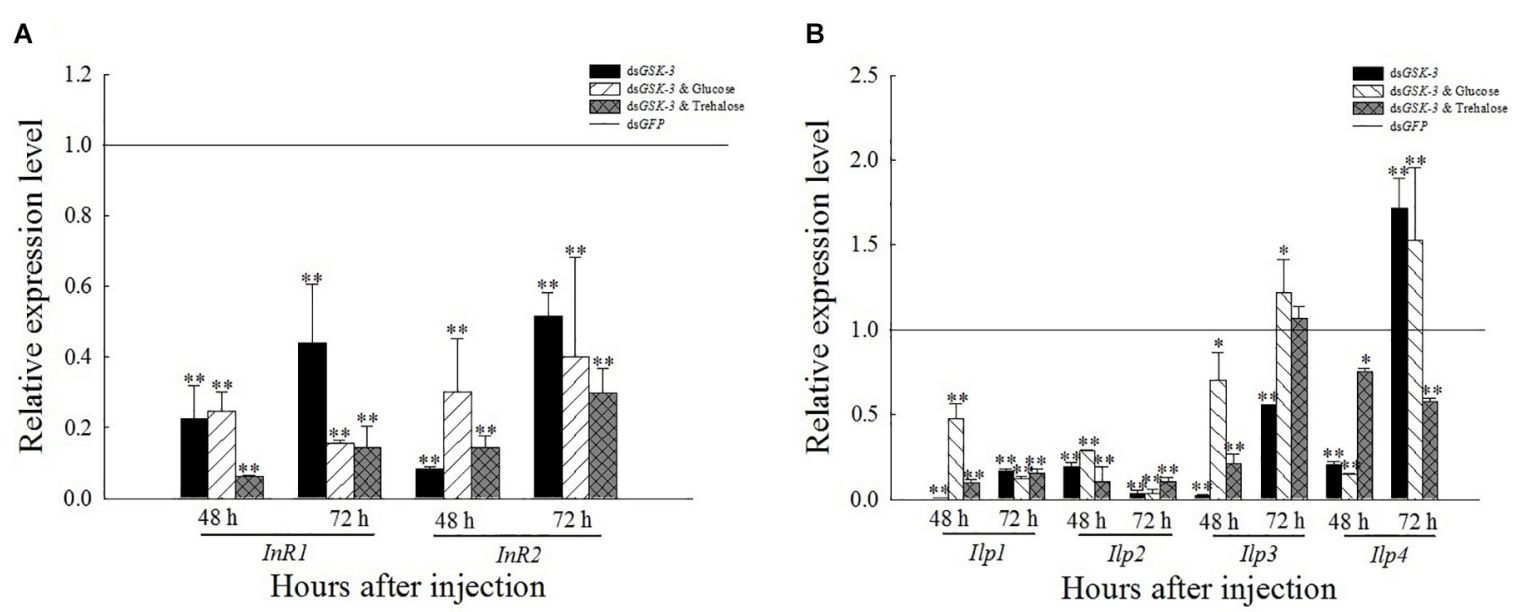

FIGURE 6 | Expression levels of regulated genes in the insulin signaling pathway after GSK-3 RNA interference. The relative expression levels of InR genes (A) and Ilp genes (B) were compared with the control dsGFP after injection in each treatment group. *Indicates significant differences at $P<0.05$ and $* *$ indicates significant differences at $P<0.01$. Error bars is the standard error. 


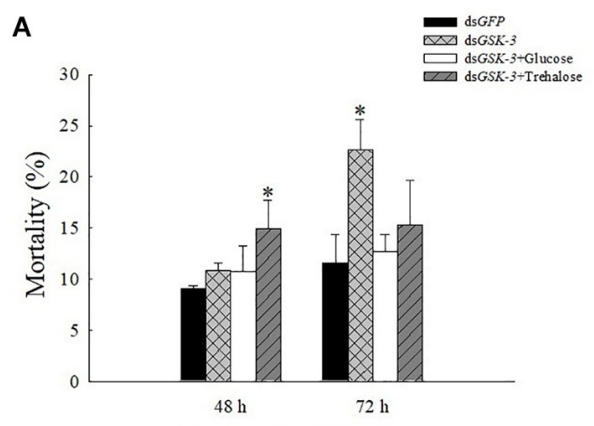

Hours after injection

C

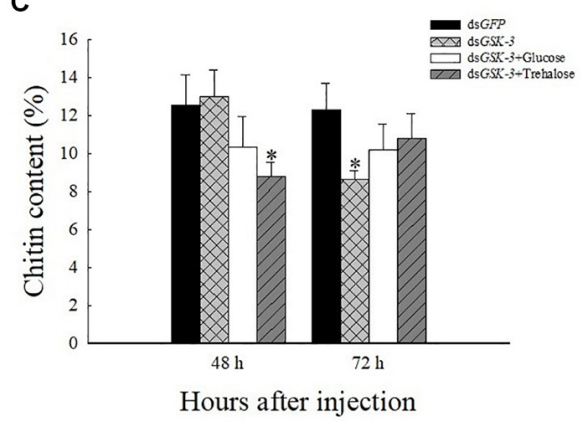

B

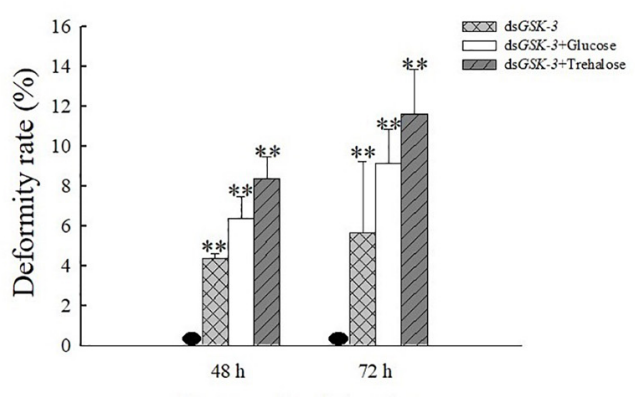

Hours after injection

: The deformity rate of dsGFP control group is 0 .

D

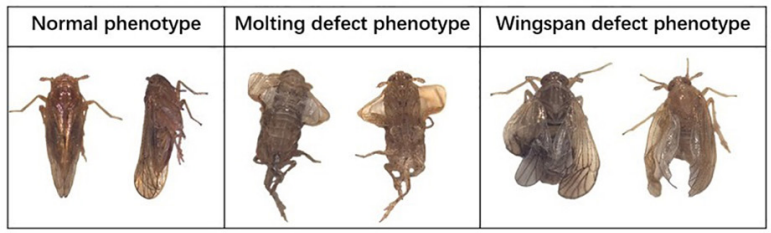

FIGURE 7 | The effect of GSK-3 gene silencing on the chitin content and phenotype of N. lugens. Mortality rate (A), deformity rate (B), chitin content (C), and Normal and abnormal phenotypes of $N$. lugens (D) were compared with the control dsGFP after injection in each treatment group. *Indicates significant differences at $P<0.05$ and $* *$ indicates significant differences at $P<0.01$. Error bars is the standard error.

After RNAi treatment, the relative content of chitin in $N$. lugens changed. $48 \mathrm{~h}$ after the injection, except for the dsGSK3 and trehalose mixed injection group, there was a significant decrease $(P<0.05)$, and the other injection groups had no significant changes. $72 \mathrm{~h}$ after dsGSK-3 injection, the content of chitin in $N$. lugens significantly decreased $(P<0.05)$, while the other injection groups did not decrease significantly (Figure 7C). These results indicate that GSK-3 gene silencing affects the metabolism of chitin and the formation of wings in N. lugens.

\section{DISCUSSION}

RNA interference has great potential for studying insect gene function, mainly by microinjecting dsRNA or siRNA into insects to inhibit gene expression (Xi et al., 2015; Li et al., 2017) or synthesized in vitro and topically applied to crops (Murphy et al., 2016). In this study, the expression levels of the GSK3 gene were extremely significantly decreased after injection in each treatment group of $N$. lugens, indicating that the RNA interference effect is obvious, and the interference effect can last up to $72 \mathrm{~h}$ (Figure 1). Previous studies have found that GSK-3 is involved in a variety of signaling pathways and plays an important regulatory role in cells (Liu et al., 2018). GSK-3 acts on the Ser332 site of insulin receptor substrate1 (IRS-1) to block the insulin-signaling pathway, thereby regulating glycogen synthesis (Liberman and Eldar-Finkelman,
2005). After insulin enters the insect, it activates $I l p$ and $I n R$ and then activates phosphatidylinositol kinase (PI3K). Activated PI3K catalyzes phosphorylation of phosphatidylinositol, which in turn causes phosphorylation of the effector Akt, which prevents phosphorylation of glycogen synthase (GSK-3), thereby promoting glycogen synthesis (Woodgett et al., 1993; Nagy et al., 2018). The effect of Ilp on glucose metabolism cannot only promote glycogen synthesis but also inhibit gluconeogenesis and conversion of excess sugar into lipids in specific tissues (Semaniuk et al., 2018; Kawabe et al., 2019). The results of this study showed that the expressions of insulin signaling pathwayrelated genes $I n R, I l p 1, I l p 2$, and $I l p 3$ were extremely significantly decreased 48 and $72 \mathrm{~h}$ after dsGSK-3 injection (Figure 6). Only the expression of Ilp4 increased extremely significantly $72 \mathrm{~h}$ after injection (Figure 6B), presumably related to its regulation of the reproduction of $N$. lugens ( $\mathrm{Lu}$ et al., 2018). At the same time, the glycogen and glucose contents of $N$. lugens were significantly or extremely significantly decreased (Figures 2A,B), indicating that N. lugens GSK-3 can regulate glycogen and glucose synthesis through the insulin signaling pathway (McManus et al., 2005).

Trehalose can act as an energy reserve for the life activities of insects under stress, such as starvation and dryness (Yasugi et al., 2017). Under various stresses, trehalose accumulation occurs in insects (Fountain et al., 2016; Tamang et al., 2017; Paithankar et al., 2018). This study found that the trehalose content increased extremely significantly $48 \mathrm{~h}$ after dsGSK-3 injection (Figure 2C), and the two trehalase activities decreased extremely 
significantly (Figures 3A,B), showing consistency. However, the trehalose content decreased extremely significantly (Figure 2C) and trehalase activity remained significantly decreased $72 \mathrm{~h}$ after injection (Figures 3A,B). TPS can affect the energy supply, growth and development, stress recovery, chitin synthesis, and other biological processes of $N$. lugens (Tang et al., 2018). When the expression of TPS and TRE in the trehalose metabolism pathway of the $N$. lugens was inhibited, the glycogen content decreased (Zhang et al., 2017b). In this study, the expressions of TPS1, TPS2, and TRE were down-regulated after GSK-3 interference (Figures $\mathbf{4 A}, \mathbf{5 A}$ ), that is, the accumulation of trehalose in $N$. lugens led to an increase in its content $48 \mathrm{~h}$ after GSK-3 RAN interference, but due to the resistance of trehalose synthesis, the content of trehalose decreased $72 \mathrm{~h}$ after injection. The expression of TPS 3 increased $48 \mathrm{~h}$ after GSK-3 interference, probably because the structure of TPS 3 is different from that of TPS1 and TPS2, so their functions are also different. Al Baki MA et al. found that the chyme content of Alpaki was increased after Ilp and InR RNAi (Al Baki et al., 2019), which is consistent with the results of this study (Figures 6A,B), that is, glycogen and glucose are converted into trehalose after dsGSK-3 injection, which leads to an increase in glucose metabolism and maintains the balance of glucose metabolism in insects, which is consistent with previous studies (Mitsumasu et al., 2010; Tang et al., 2012).

The metabolism of glycogen requires a combination of enzymes, mainly regulated by glycogen synthase (GS) and glycogen phosphorylase (GP) (Zhang et al., 2017b). GSK-3 can phosphorylate glycogen synthase to inhibit glycogen synthesis (Contreras et al., 2016). In our study, the expression of GS and GP was extremely significantly decreased 48 and $72 \mathrm{~h}$ after dsGSK3 injection (Figure 5D). In animals, glycogen plays a role in different tissues, and hepatic glycogen can be decomposed into glucose during hypoglycemia to control blood sugar stability; glycogen can also supply energy to organisms through the glycolysis pathway (Roach et al., 2012; Falkowska et al., 2015). In this study, the expression of the PGM1 gene in the energy metabolism pathway decreased slightly $48 \mathrm{~h}$ after injection but increased extremely significantly $72 \mathrm{~h}$ after injection (Figure 5B). In addition, the expression of G6P associated with glycogen degradation returned to a level similar to that of the dsGFP group after a significant increase after injection (Figure 5C; Klotz and Forchhammer, 2017). That is, the expression of GSK-3 can inhibit the metabolism of carbohydrates.

The reasonable intake of dietary sugar is essential for the growth and development of insects, while the trehalose of insects is mostly synthesized by the intake of glucose (Thompson et al., 2003; Mattila and Hietakangas, 2017). Under a high-sugar diet, the glucose content in Drosophila increased, while the expression of adiponectin $(A k h)$ was down-regulated, and the glycogen content was reduced (Gáliková et al., 2015; Hemphill et al., 2018). Our results showed that the glycogen and glucose levels of two mixed injection groups showed extremely significant decreases compared with the control group $48 \mathrm{~h}$ after injection; the glycogen and glucose levels increased significantly $72 \mathrm{~h}$ after injection of a mixture of dsGSK-3 and glucose, and the mixed injection group of dsGSK-3 and trehalose returned to a level similar to the control group (Figures 2A,B). In contrast, the two mixed injection groups had no significant effect on the trehalose content (Figure 2C), but both types of trehalase activity decreased significantly $48 \mathrm{~h}$ after injection and rose to a level similar to the control group $72 \mathrm{~h}$ after injection (Figures $3 \mathrm{~A}, \mathbf{B}$ ). TRE1 mainly exists in the midgut of $N$. lugens and regulates the decomposition of endogenous trehalose; TRE2 mainly absorbs and assimilates exogenous trehalose (Tang et al., 2016). Therefore, the expression level of TRE1-2 was significantly increased $48 \mathrm{~h}$ after a mixture of dsGSK-3 and glucose injection and $72 \mathrm{~h}$ after a mixture of dsGSK-3 and trehalose injection (Figure 4A). HK catalyzes the conversion of glucose to glucose-6-phosphate, and GFAT decomposes fructose-6-phosphate. The expression of GFAT, HK, and G6PI1 in the chitin pathway increased or significantly increased $48 \mathrm{~h}$ after injection of a mixture of dsGSK-3 and glucose (Figures 4B,C). In vitro injection of glucose or trehalose can compensate for the interference of dsGSK-3 in the energy metabolism and chitin synthesis of $N$. lugens, but it seems that $N$. lugens is more sensitive to changes in the glucose content (Masumura et al., 2000; Ugrankar et al., 2015).

The growth and development of insects are closely related to the biosynthesis of chitin (Merzendorfer and Zimoch, 2003; Muthukrishnan et al., 2018). Trehalose is the first gene in the chitin biosynthesis pathway of insects, which regulates chitin synthase (Zhao et al., 2016; Tang et al., 2017). Previous studies have shown that the inhibition of CHS gene expression will lead to a decrease in the content of chitin, abnormal phenotypes and an increase in mortality of $N$. lugens (Yang et al., 2017; Li et al., 2017; Pan et al., 2019). Our results showed a decrease or a significant decrease in TRE expression after dsGSK-3 injection (Figure 4A). At the same time, compared with the dsGFP group, the expression of CHS1 was similar $48 \mathrm{~h}$ after dsGSK-3 injection; the expression of CHS1a was extremely significantly increased, the expression of $\mathrm{CHS} 1 \mathrm{~b}$ was extremely significantly decreased, and the expression of three CHS genes was significantly decreased $72 \mathrm{~h}$ after injection (Figure 4D). At the same time, the content of chitin was significantly reduced $48 \mathrm{~h}$ after dsGSK-3 and trehalose injection and $72 \mathrm{~h}$ after dsGSK-3 injection (Figure 7C). This suggests that dsGSK-3 has different regulatory effects on different chitin synthase genes, but ultimately inhibits their expression, which may be related to the functional specificity of chitin synthase (Arakane et al., 2009; Merzendorfer, 2011). Our research also found that $N$. lugens had difficulty molting, deformed wings, and increased mortality after dsGSK-3 injection (Figures 7A,B,D). In addition, the expression of G6PI also increased $48 \mathrm{~h}$ after dsGSK-3 injection and decreased after $72 \mathrm{~h}$ (Figure 4C). The interference of GSK-3 has an effect on the expression of genes involved in the chitin biosynthesis pathway of N. lugens.

\section{CONCLUSION}

GSK-3 RNAi can effectively inhibit the expression of target genes in N. lugens; GSK-3 can down-regulate the expression of energy metabolism pathway-related genes and trehalase activity, thereby reducing the glycogen and glucose content, increasing the trehalose content, and regulating insect trehalose balance; GSK-3 can regulate genes involved in the chitin biosynthesis pathway 
of $N$. lugens, affecting its chitin synthesis, leading to phenotypic abnormalities and even death.

\section{DATA AVAILABILITY STATEMENT}

All datasets generated for this study are included in the article/supplementary material.

\section{AUTHOR CONTRIBUTIONS}

Y-JD, G-YL, and CL conceived and manuscript structure design. C-DX, YW, and S-GW performed the current articles collection and related metabolic genes' analysis. Y-JD, Z-SZ, and CL

\section{REFERENCES}

Al Baki, M. A., Lee, D. W., Jung, J. K., and Kim, Y. (2019). Insulin-like peptides of the legume pod borer, Maruca vitrata, and their mediation effects on hemolymph trehalose level, larval development, and adult reproduction. Arch. Insect. Biochem. Physiol. 100:e21524. doi: 10.1002/arch. 21524

Arakane, Y., Dixit, R., Begum, K., Park, Y., Specht, C. A., Merzendorfer, H., et al. (2009). Analysis of functions of the chitin deacetylase gene family in Tribolium castaneum. Insect. Biochem. Mol. Biol. 39, 355-365. doi: 10.1016/j.ibmb.2009. 02.002

Arrese, E. L., and Soulages, J. L. (2010). Insect fat body: energy, metabolism, and regulation. Annu. Rev. Entomol. 55, 207-225. doi: 10.1146/annurev-ento112408-085356

Avonce, N., Mendoza-Vargas, A., Morett, E., and Iturriaga, G. (2006). Insights on the evolution of trehalose biosynthesis. BMC Evol. Biol. 6:109. doi: 10.1186/ 1471-2148-6-109

Cao, C. W., and Gao, C. Q. (2009). Experimental Techniques of Insect Biochemistry and Molecular Biology. Harbin: Northeast Forestry University Press, 24-26.

Carlson, G. M., Dienel, G. A., and Colbran, R. J. (2018). Introduction to the thematic minireview series: brain glycogen metabolism. J. Biol. Chem. 293, 7087-7088. doi: 10.1074/jbc.TM118.002642

Chang, C. H., Huang, J. J., Yeh, C. Y., Tang, C. H., Hwang, L. Y., and Lee, T. H. (2018). Salinity effects on strategies of glycogen utilization in livers of Euryhaline Milkfish (Chanos chanos) under hypothermal stress. Front. Physiol. 9:81. doi: 10.3389/fphys.2018.00081

Chen, Q. W., Jin, S., Zhang, L., Shen, Q. D., Wei, P., Wei, Z. M., et al. (2018). Regulatory functions of trehalose-6-phosphate synthase in the chitin biosynthesis pathway in Tribolium castaneum (Coleoptera: Tenebrionidae) revealed by RNA interference. Bull. Entomol. Res. 108, 388-399. doi: 10.1017/ S000748531700089X

Contreras, C. J., Segvich, D. M., Mahalingan, K., Chikwana, V. M., Kirley, T. L., Hurley, T. D., et al. (2016). Incorporation of phosphate into glycogen by glycogen synthase. Arch. Biochem Biophys. 597, 21-29. doi: 10.1016/j.abb.2016. 03.020

Diptaningsari, D., Trisyono, Y. A., Purwantoro, A., and Wijonarko, A. (2019). Inheritance and realized heritability of resistance to imidacloprid in the Brown Planthopper, Nilaparvata lugens (Hemiptera: Delphacidae), from Indonesia. J. Econ. Entomol. 112, 1831-1837. doi: 10.1093/jee/toz090

Duran, J., Tevy, M. F., Garcia-Rocha, M., Calbó, J., Milán, M., and Guinovart, J. J. (2012). Deleterious effects of neuronal accumulation of glycogen in flies and mice. EMBO Mol. Med. 4, 719-729. doi: 10.1002/emmm.201200241

Falkowska, A., Gutowska, I., Goschorska, M., Nowacki, P., Chlubek, D., and Baranowska-Bosiacka, I. (2015). Energy metabolism of the brain, including the cooperation between astrocytes and neurons, especially in the context of glycogen metabolism. Int. J. Mol. Sci. 16, 25959-25981. doi: 10.3390/ ijms161125939

Fountain, T., Melvin, R. G., Ikonen, S., Ruokolainen, A., Woestmann, L., Hietakangas, V., et al. (2016). Oxygen and energy availability interact to wrote the manuscript. All authors contributed to the article and approved the submitted version.

\section{FUNDING}

We thank the Regional First-class Discipline Construction of Guizhou Province [No. (2017)85], the scientific research funds of Guiyang University [No. GYU-KY-(2021)], the Provincial Key and Special Subject of Guizhou Province-Ecology [No. ZDXK(2015)11], Training Project for High-Level Innovative Talents in Guizhou Province [No. 2016 (4020)], and the Program for Academician Workstation in Guiyang University (20195605) for financial support.

determine flight performance in the Glanville fritillary butterfly. J. Exp. Biol. 219, 1488-1494. doi: 10.1242/jeb.138180

Frame, S., and Cohen, P. (2001). GSK3 takes centre stage more than 20 years after its discovery. Biochem. J. 359, 1-16.

Gáliková, M., Diesner, M., Klepsatel, P., Hehlert, P., Xu, Y., Bickmeyer, I., et al. (2015). Energy homeostasis control in Drosophila adipokinetic hormone mutants. Genetics 201, 665-683. doi: 10.1534/genetics.115.178897

Ghaffar, M. B., Pritchard, J., and Ford-Lloyd, B. (2011). Brown planthopper (N. lugens Stål) feeding behaviour on rice germplasm as an indicator of resistance. PLoS One 6:e22137. doi: 10.1371/journal.pone.0022137

Guo, J., Xu, Y., Yang, X. S., Sun, X. H., Sun, Y., and Zhou, D. (2019). TRE1 and CHS1 contribute to deltamethrin resistance in Culex pipiens pallens. Arch. Insect. Biochem. Physiol. 100:e21538. doi: 10.1002/arch.21538

Hemphill, W., Rivera, O., and Talbert, M. (2018). RNA-sequencing of Drosophila melanogaster head tissue on high-sugar and high-fat diets. G3 8, 279-290. doi: $10.1534 / \mathrm{g} 3.117 .300397$

Jing, S. L., Zhao, Y., Du, B., Chen, R. Z., Zhu, L. L., and He, G. C. (2017) Corrigendum to "Genomics of interaction between the brown planthopper and rice” [Curr. Opin. Insect Sci. 19 (2017) 82-87]. Curr. Opin. Insect. Sci. 27:118. doi: 10.1016/j.cois.2018.01.002

Kang, K., Yue, L., Xia, X., Liu, K., and Zhang, W. (2019). Comparative metabolomics analysis of different resistant rice varieties in response to the brown planthopper Nilaparvata lugens Hemiptera: Delphacidae. Metabolomics 15:62. doi: 10.1007/s11306-019-1523-4

Kawabe, Y., Waterson, H., and Mizoguchi, A. (2019). Bombyxin (Bombyx InsulinLike Peptide) increases the respiration rate through facilitation of carbohydrate catabolism in Bombyx mori. Front. Endocrinol. 10:150. doi: 10.3389/fendo.2019. 00150

Khan, I., Tantray, M. A., Alam, M. S., and Hamid, H. (2017). Natural and synthetic bioactive inhibitors of glycogen synthase kinase. Eur. J. Med. Chem. 125, 464-477. doi: 10.1016/j.ejmech.2016.09.058

Klotz, A., and Forchhammer, K. (2017). Glycogen, a major player for bacterial survival and awakening from dormancy. Future Microbiol. 12, 101-104. doi: 10.2217/fmb-2016-0218

Li, T. C., Chen, J., Fan, X. B., Chen, W. W., and Zhang, W. Q. (2017). MicroRNA and dsRNA targeting chitin synthase A reveal a great potential for pest management of the hemipteran insect Nilaparvata lugens. Pest. Manag. Sci. 73, 1529-1537. doi: 10.1002/ps.4492

Liberman, Z., and Eldar-Finkelman, H. (2005). Serine 332 phosphorylation of insulin receptor substrate- 1 by glycogen synthase kinase- 3 attenuates insulin signaling. J. Biol. Chem. 280, 4422-4428. doi: 10.1074/jbc.M410610200

Liu, X., and Klein, P. S. (2018). Glycogen synthase kinase-3 and alternative splicing. Wiley Interdiscip. Rev. RNA 9:e1501. doi: 10.1002/wrna.1501

Liu, X. J., Sun, Y. W., Li, D. Q., Li, S., Ma, E. B., and Zhang, J. Z. (2018). Identification of LmUAP1 as a 20-hydroxyecdysone response gene in the chitin biosynthesis pathway from the migratory locust, Locusta migratoria. Insect Sci. 25, 211-221. doi: 10.1111/1744-7917.12406

Lu, K., Chen, X., Li, W. R., Li, Y., Zhang, Z. C., and Zhou, Q. (2018). Insulinlike peptides and DNA/tRNA methyltransferases are involved in the nutritional 
regulation of female reproduction in Nilaparvata lugens (Stål). Gene 639, 96-105. doi: 10.1016/j.gene.2017.10.011

Maqbool, M., Mobashir, M., and Hoda, N. (2016). Pivotal role of glycogen synthase kinase-3: a therapeutic target for Alzheimer's disease. Eur. J. Med. Chem. 107, 63-81. doi: 10.1016/j.ejmech.2015.10.018

Masumura, M., Satake, S., Saegusa, H., and Mizoguchi, A. (2000). Glucose stimulates the release of bombyxin, an insulin-related peptide of the silkworm Bombyx mori. Gen. Comp. Endocrinol. 118, 393-399. doi: 10.1006/gcen.1999. 7438

Matsuda, H., Yamada, T., Yoshida, M., and Nishimura, T. (2015). Flies without trehalose. J. Biol. Chem. 290, 1244-1255. doi: 10.1074/jbc.M114.619411

Mattila, J., and Hietakangas, V. (2017). Regulation of carbohydrate energy metabolism in Drosophila melanogaster. Genetics 207, 1231-1253. doi: 10.1534/ genetics.117.199885

McManus, E. J., Sakamoto, K., Armit, L. J., Ronaldson, L., Shpiro, N., Marquez, R., et al. (2005). Role that phosphorylation of GSK3 plays in insulin and Wnt signalling defined by knockin analysis. Embo J. 24, 1571-1583. doi: 10.1038/sj. emboj.7600633

Merzendorfer, H. (2006). Insect chitin synthases: a review. J. Comp. Physiol. B 176, 1-15. doi: 10.1007/s00360-005-0005-3

Merzendorfer, H. (2011). The cellular basis of chitin synthesis in fungi and insects: common principles and differences. Eur. J. Cell Biol. 90, 759-769. doi: 10.1016/ j.ejcb.2011.04.014

Merzendorfer, H., and Zimoch, L. (2003). Chitin metabolism in insects: structure, function and regulation of chitin synthases and chitinases. J. Exp. Biol. 206, 4393-4412. doi: 10.1242/jeb.00709

Mitsumasu, K., Kanamori, Y., Fujita, M., Iwata, K., Tanaka, D., Kikuta, S., et al. (2010). Enzymatic control of anhydrobiosis-related accumulation of trehalose in the sleeping chironomid, Polypedilum vanderplanki. FEBS J. 277, 4215-4228. doi: 10.1111/j.1742-4658.2010.07811.x

Murphy, K. A., Tabuloc, C. A., Cervantes, K. R., and Chiu, J. C. (2016). Ingestion of genetically modified yeast symbiont reduces fitness of an insect pest via RNA interference. Sci. Rep. 6:22587. doi: 10.1038/srep22587

Mury, F. B., Lugon, M. D., Da Fonseca, R. N., Silva, J. R., Berni, M., Araujo, H. M., et al. (2016). Glycogen Synthase Kinase-3 is involved in glycogen metabolism control and embryogenesis of Rhodnius prolixus. Parasitology 143, 1569-1579. doi: 10.1017/S0031182016001487

Muthukrishnan, S., Arakane, Y., Yang, Q., Zhang, C. X., Zhang, J., Zhang, W., et al. (2018). Future questions in insect chitin biology: a microreview. Arch. Insect. Biochem. Physiol. 98:e21454. doi: 10.1002/arch.21454

Nagy, L., Márton, J., Vida, A., Kis, G., Bokor, É, Kun, S., et al. (2018). Glycogen phosphorylase inhibition improves beta cell function. Br. J. Pharmacol. 175, 301-319. doi: 10.1111/bph.13819

Paithankar, J. G., Raghu, S. V., and Patil, R. K. (2018). Concomitant changes in radiation resistance and trehalose levels during life stages of Drosophila melanogaster suggest radio-protective function of trehalose. Int. J. Radiat. Biol. 94, 576-589. doi: 10.1080/09553002.2018.1460499

Pan, B. Y., Li, G. Y., Wu, Y., Zhou, Z. S., Zhou, M., and Li, C. (2019). Glucose utilization in the regulation of chitin synthesis in brown planthopper. J. Insect Sci. 19:3. doi: 10.1093/jisesa/iez081

Prats, C., Graham, T. E., and Shearer, J. (2018). The dynamic life of the glycogen granule. J. Biol. Chem. 293, 7089-7098. doi: 10.1074/jbc.R117.802843

Qiu, J., He, Y., Zhang, J., Kang, K., Li, T., and Zhang, W. (2016). Discovery and functional identification of fecundity-related genes in the brown planthopper by large-scale RNA interference. Insect. Mol. Biol. 25, 724-733. doi: 10.1111/ imb. 12257

Roach, P. J., Depaoli-Roach, A. A., Hurley, T. D., and Tagliabracci, V. S. (2012). Glycogen and its metabolism: some new developments and old themes. Biochem. J. 441, 763-787. doi: 10.1042/BJ20111416

Santiago-Martínez, M. G., Encalada, R., Lira-Silva, E., Pineda, E., Gallardo-Pérez, J. C., Reyes-García, M. A., et al. (2016). The nutritional status of Methanosarcina acetivorans regulates glycogen metabolism and gluconeogenesis and glycolysis fluxes. FEBS J. 283, 1979-1999. doi: 10.1111/febs.13717

Sato, A., and Shibuya, H. (2018). Glycogen synthase kinase $3 ß$ functions as a positive effector in the WNK signaling pathway. PLoS One 13:e0193204. doi: 10.1371/journal.pone.0193204

Semaniuk, U. V., Gospodaryov, D. V., Feden'ko, K. M., Yurkevych, I. S., Vaiserman, A. M., Storey, K. B., et al. (2018). Insulin-like peptides regulate feeding preference and metabolism in Drosophila. Front. Physiol. 9:1083. doi: 10.3389/ fphys.2018.01083

Shi, J. F., Mu, L. L., Chen, X., Guo, W. C., and Li, G. Q. (2016). RNA interference of chitin synthase genes inhibits chitin biosynthesis and affects larval performance in Leptinotarsa decemlineata (Say). Int. J. Biol. Sci. 12, 1319-1331. doi: 10.7150/ ijbs. 14464

Shukla, E., Thorat, L. J., Nath, B. B., and Gaikwad, S. M. (2015). Insect trehalase: physiological significance and potential applications. Glycobiology 25, 357-367. doi: $10.1093 /$ glycob/cwu125

Tamang, A. M., Kalra, B., and Parkash, R. (2017). Cold and desiccation stress induced changes in the accumulation and utilization of proline and trehalose in seasonal populations of Drosophila immigrans. Comp. Biochem. Physiol. A Mol. Integr. Physiol. 203, 304-313. doi: 10.1016/j.cbpa.2016

Tang, B., Chen, J., Yao, Q., Pan, Z. Q., Xu, W. H., Wang, S. G., et al. (2010). Characterization of a trehalose-6-phosphate synthase gene from Spodoptera exigua and its function identification through RNA interference. J. Insect. Physiol. 56, 813-821. doi: 10.1016/j.jinsphys.2010.02.009

Tang, B., Wang, S., Wang, S. G., Wang, H. J., Zhang, J. Y., and Cui, S. Y. (2018). Invertebrate trehalose-6-phosphate synthase gene: genetic architecture, biochemistry, physiological function, and potential applications. Front. Physiol. 9:30. doi: $10.3389 /$ fphys.2018.00030

Tang, B., Wei, C. J., Wang, S. G., and Zhang, W. Q. (2012). Progress in gene features and functions of insect trehalases. Acta Entomol. Sin. 55, 1315-1321. doi: 10.16380/j.kcxb.2012.11.008

Tang, B., Wei, P., Zhao, L. N., Shi, Z. K., Shen, Q. D., Yang, M. M., et al. (2016). Knockdown of five trehalase genes using RNA interference regulates the gene expression of the chitin biosynthesis pathway in Tribolium castaneum. BMC Biotechnol. 16:67. doi: 10.1186/s12896-016-0297-2

Tang, B., Yang, M. M., Shen, Q. D., Xu, Y. X., Wang, H. J., and Wang, S. G. (2017). Suppressing the activity of trehalase with validamycin disrupts the trehalose and chitin biosynthesis pathways in the rice brown planthopper, Nilaparvata lugens. Pestic. Biochem. Physiol. 137, 81-90. doi: 10.1016/j.pestbp.2016.10.003

Thompson, S. N., Borchardt, D. B., and Wang, L. W. (2003). Dietary nutrient levels regulate protein and carbohydrate intake, gluconeogenic/glycolytic flux and blood trehalose level in the insect Manduca sexta L. J. Comp. Physiol. B 173, 149-163. doi: 10.1007/s00360-002-0322-8

Ugrankar, R., Berglund, E., Akdemir, F., Tran, C., Kim, M. S., Noh, J., et al. (2015). Drosophila glucome screening identifies Cklalpha as a regulator of mammalian glucose metabolism. Nat. Commun. 6:7102. doi: 10.1038/ncomms8102

Wang, P., and Granados, R. R. (2010). Molecular structure of the peritrophic membrane (PM): identification of potential PM target sites for insect control (p 110-118). Arch. Insect. Biochem. Physiol. 2, 110-118. doi: 10.1002/arch.1041

Wei, C., and Wei, H. X. (2015). Expression analysis of GSK-3 $\beta$ in diapause pupal brains in the cotton bollworm. Helicoverpa armigera. Insect Sci. 22, 597-605. doi: 10.1111/1744-7917.12215

Wen, X., Wang, S., Duman, J. G., Arifin, J. F., Juwita, V., Goddard, W. A., et al. (2016). Antifreeze proteins govern the precipitation of trehalose in a freezingavoiding insect at low temperature. Proc. Natl. Acad. Sci. U.S.A. 113, 6683-6688. doi: $10.1073 /$ pnas. 1601519113

Woodgett, J. R., Plyte, S. E., Pulverer, B. J., Mitchell, J. A., and Hughes, K. (1993). Roles of glycogen synthase kinase-3 in signal transduction. Biochem. Soc. Trans. 21, 905-907. doi: 10.1042/bst0210905

Xi, Y., Pan, P. L., Ye, Y. X., Yu, B., Xu, H. J., and Zhang, C. X. (2015). Chitinase-like gene family in the brown planthopper, Nilaparvata lugens. Insect. Mol. Biol. 24, 29-40. doi: 10.1111/imb.12133

Xu, G. F., Zhang, J., Lyu, H., Liu, J., Ding, Y., Feng, Q., et al. (2017). BmCHSA-2b, a Lepidoptera specific alternative splicing variant of epidermal chitin synthase, is required for pupal wing development in Bombyx mori. Insect. Biochem. Mol. Biol. 87, 117-126. doi: 10.1016/j.ibmb.2017

Yamada, T., Habara, O., Kubo, H., and Nishimura, T. (2018). Correction: fat body glycogen serves as a metabolic safeguard for the maintenance of sugar levels in Drosophila. Development 145:dev165910. doi: 10.1242/dev.165910

Yang, M. M., Zhao, L. N., Shen, Q. D., Xie, G. Q., Wang, S. G., and Tang, B. (2017). Knockdown of two trehalose-6-phosphate synthases severely affects chitin metabolism gene expression in the brown planthopper Nilaparvata lugens. Pest. Manag. Sci. 73, 206-216. doi: 10.1002/ps.4287

Yang, W. J., Wu, Y. B., Chen, L., Xu, K. K., Xie, Y. F., and Wang, J. J. (2015). Two chitin biosynthesis pathway genes in Bactrocera dorsalis (Diptera: 
Tephritidae): molecular characteristics, expression patterns, and roles in LarvalPupal transition. J. Econ. Entomol. 108, 2433-2442. doi: 10.1093/jee/tov186

Yang, Y. X., Xu, S. X., Xu, J. X., Guo, Y., and Yang, G. (2014). Adaptive evolution of mitochondrial energy metabolism genes associated with increased energy demand in flying insects. PLoS One 9:e99120. doi: 10.1371/journal.pone. 0099120

Yasugi, T., Yamada, T., and Nishimura, T. (2017). Adaptation to dietary conditions by trehalose metabolism in Drosophila. Sci. Rep. 7:1619. doi: 10.1038/s41598017-01754-9

Yu, N., Christiaens, O., Liu, J., Niu, J., Cappelle, K., Caccia, S., et al. (2013). Delivery of dsRNA for RNAi in insects: an overview and future directions. Insect Sci. 20, 4-14. doi: 10.1111/j.1744-7917.2012.01534

Zhang, J. L., Yuan, X. B., Chen, S. J., Chen, H. H., Xu, N., Xue, W. H., et al. (2018). The histone deacetylase NlHDAC1 regulates both female and male fertility in the brown planthopper, Nilaparvata lugens. Open Biol. 8:180158. doi: 10.1098/rsob.180158

Zhang, L., Qiu, L. Y., Yang, H. L., Wang, H. J., Zhou, M., Wang, S. G., et al. (2017a). Study on the effect of wing bud chitin metabolism and its developmental network genes in the Brown Planthopper, Nilaparvata lugens, by knockdown of TRE gene. Front. Physiol. 8:750. doi: 10.3389/fphys.2017.00750

Zhang, L., Wang, H. J., Chen, J. Y., Shen, Q. D., Wang, S. G., Xu, H. X., et al. (2017b). Glycogen phosphorylase and glycogen synthase: gene cloning and expression analysis reveal their role in trehalose metabolism in the Brown Planthopper, Nilaparvata lugens Stål (Hemiptera: Delphacidae). J. Insect. Sci. 17:42. doi: $10.1093 /$ jisesa/iex015
Zhao, L. N., Wei, P., Guo, H. S., Wang, S. G., and Tang, B. (2014). Suppressing the expression of a forkhead transcription factor disrupts the chitin biosynthesis pathway in Spodoptera exigua. Arch. Insect. Biochem. Physiol. 86, 4-18. doi: 10.1002/arch. 21145

Zhao, L. N., Yang, M. M., Shen, Q. D., Liu, X. J., Shi, Z. K., Wang, S. G., et al. (2016). Functional characterization of three trehalase genes regulating the chitin metabolism pathway in rice brown planthopper using RNA interference. Sci. Rep. 6:27841. doi: 10.1038/srep27841

Zhu, J. J., Jiang, F., Wang, X. H., Yang, P. C., Bao, Y. Y., Zhao, W., et al. (2017). Genome sequence of the small brown planthopper, Laodelphax striatellus. GigaScience 6, 1-12. doi: 10.1093/gigascience/gix109

Zhu, K. Y., Merzendorfer, H., Zhang, W., Zhang, J., and Muthukrishnan, S. (2016). Biosynthesis, turnover, and functions of chitin in insects. Annu. Rev. Entomol. 61, 177-196. doi: 10.1146/annurev-ento-010715-023933

Conflict of Interest: The authors declare that the research was conducted in the absence of any commercial or financial relationships that could be construed as a potential conflict of interest.

Copyright (c) 2020 Ding, Li, Xu, Wu, Zhou, Wang and Li. This is an open-access article distributed under the terms of the Creative Commons Attribution License (CC BY). The use, distribution or reproduction in other forums is permitted, provided the original author(s) and the copyright owner(s) are credited and that the original publication in this journal is cited, in accordance with accepted academic practice. No use, distribution or reproduction is permitted which does not comply with these terms. 